\title{
Health Care and Pharmacy Practice in Jordan
}

\author{
Lama H Nazer and Haitham Tuffaha
}

\section{INTRODUCTION}

$\int$ ord ordan is an Arab country located in the north of the Arabian Peninsula, west of Asia. ${ }^{1}$ It occupies an area of about $92000 \mathrm{~km}^{2}$, with an estimated total population of about 9.5 million, most of whom reside in the capital, Amman. ${ }^{1,2}$ Jordan is renowned for its high-quality health care services and is considered one of the major destinations for medical tourism in the Middle East and North Africa region. ${ }^{3}$

This paper aims to describe current health care and pharmacy practice in Jordan. It is part of a series of invited papers on health care systems in countries around the world. The paper is structured according to the building blocks outlined in the World Health Organization's Health Systems Framework. ${ }^{4}$

\section{HEALTH SYSTEM LEADERSHIP, GOVERNANCE, AND HEALTH CARE FINANCING}

The health care system in Jordan consists of 2 main sectors: the public/semipublic sector and the private sector. Both sectors include hospitals, primary care clinics, pharmacies, and other ancillary services. There are a total of 106 private and public hospitals in Jordan, providing 12081 beds. The public sector accounts for the majority of these hospital beds (67\%), with the remainder being provided by private hospitals. In Jordan, the hospital bed rate of about 18 beds per 10000 people is higher than the bed rates in several other Arab countries in the region but lower than the global rate. With the recent increase in the population and the high influx of refugees to Jordan, the current bed rate is considered suboptimal. ${ }^{5}$

Primary health care clinics in Jordan provide quick access to medical care and offer vaccination, maternity and child care, and chronic disease management services. They operate in urban as well as rural areas and range in size from small individual clinics to comprehensive multiclinic centres, depending on the area and population served.

Home health care in Jordan is limited and is provided mainly through the private sector. Although home care services are intended to reduce the costs of treatment, most patients in Jordan cannot afford home services, because the costs are not covered by public or private health insurance. Long-term care facilities do not exist in Jordan, so patients must stay in acute care institutions for long periods (up to several months in some cases). With the aging of the Jordanian population, home health care and long-term care facilities are needed to reduce the burden on acute care resources.

In addition to the public and private sectors, a significant portion of health care in Jordan is provided through programs led by the United Nations and nongovernmental humanitarian agencies. The United Nations Relief and Works Agency (UNRWA) has been providing health care to Palestinian refugees since 1950 . The UNRWA clinics serve more than 1.1 million people, which is about half the population of registered Palestinian refugees in the country. ${ }^{6}$ For refugees who require hospital care, the UNRWA helps by contracting beds or partially reimbursing costs incurred for inpatient care at public and private health care facilities. ${ }^{7}$

Over the past few years, the United Nations High Commissioner for Refugees (UNHCR), with the support of the Jordanian Ministry of Health, has been providing medical care to Syrian refugees inside camps. However, the health care needs of the larger population of refugees living outside the camps are not fully met. ${ }^{8}$ Until late 2014, the Jordanian Ministry of Health provided health care free of charge to all Syrian refugees registered with the UNHCR. However, this was a large burden on the health care system, and free access to health care was withdrawn. Therefore, Syrian refugees living outside camps are now required to pay out of pocket at the same rate as uninsured Jordanians. Although the rates at public institutions are highly subsidized, this cost can be a considerable burden on the many families who are financially vulnerable. Such families may decide to forgo health care services because of the cost, especially for chronic conditions that may be considered as less urgent (or requiring less care) in the short term. ${ }^{9}$

The health care sectors in Jordan function independently, and there is no national electronic health records system. The 
availability of electronic patient records and the utilization of electronic prescribing are not universal in Jordanian hospitals. However, in October 2009, the government undertook an initiative to implement a national e-health system, under the name Hakeem. ${ }^{10}$ The system is based on WorldVistA, the opensource version of the US Department of Veterans Affairs electronic health records platform known as VistA. ${ }^{11}$ Several hospitals and health centres have implemented the system, and the goal is to connect all public hospitals and clinics, as well as university hospitals. ${ }^{10,11}$

Another major national governmental initiative in Jordan was the development of a national electronic medical library, referred to as the ELM. ${ }^{12}$ The ELM gives health care workers and students in Jordan free access to up-to-date, evidence-based resources. It includes a large number of electronic medical books, journals, and other resources that typically require expensive yearly subscriptions. The goal of developing the ELM is to promote evidence-based practice and medical research in all parts of Jordan, which would ultimately elevate the quality of health care.

According to the latest population census, about $70 \%$ of Jordanians and 55\% of the Kingdom's overall population are insured. However, there is considerable geographic variation in the population with health care insurance. The majority of Jordanians have insurance with the public sector (about $80 \%$ ), while the remainder have coverage through private insurance, the UNRWA, and other sources. All children less than 6 years old and citizens aged 60 years or older are eligible for insurance with the public health care sector. ${ }^{13}$

Total health care expenditure in 2012, as a percentage of gross domestic product (GDP), was $7.58 \%$, with over $60 \%$ of the spending in the public sector. Direct out-of-pocket health spending by citizens accounted for about $25 \%$ of total health spending. The proportion of spending on medicines was about one-fourth of health care spending and constituted $2 \%$ of GDP. For a middle-income country with a small elderly population $(<5 \%)$, this level of expenditure on medicines is considered high. For example, for the same year, expenditures on medicines in the European Union represented 1.6\% of GDP. ${ }^{5}$

\section{ACCESS TO MEDICAL PRODUCTS, VACCINES, AND TECHNOLOGY}

Jordan has a well-established local pharmaceutical manufacturing sector, which covers up to $25 \%$ of the country's needs. The rest of the medications are imported through drug wholesalers and importers. ${ }^{14}$ All medicines in the Jordanian market must be registered with the Jordan Food and Drug Administration (JFDA). As an independent institution, the JFDA regulates drugs and ensures their safety, quality, and affordability. All registered medications have a fixed national retail price that is determined by the JFDA. ${ }^{15}$

To contain the increasing cost of pharmaceuticals, the Jordan Rational Drug List (JRDL) was established. Seventeen national drug formulary technical committees, covering all relevant medical specialties, provide advice on periodic revisions and updates of the JRDL. ${ }^{16}$ The list is used to update the Jordan National Drug Formulary, which in turn is used to guide the procurement of pharmaceuticals in the public sector through the Joint Procurement Department. ${ }^{16,17}$

Economic evaluation of new drugs has become a requirement for drug pricing since 2012; however, the use of economic evaluation in pricing or to inform listings in the JRDL remains very limited because of the lack of local expertise in pharmacoeconomics, as well as the absence of clear guidelines about the role of economic evaluation in informing reimbursement decisions. ${ }^{16,18}$ That being said, the establishment of the Jordan Chapter of the International Society for Pharmacoeconomics and Outcomes Research (also known as ISPOR) might be instrumental in building pharmacoeconomics capacity in the Kingdom.

At public health care facilities, all medicines are provided free of charge for patients with health insurance. For those with private insurance, medical coverage and the level of copayment (i.e., out-of-pocket payment) depend on the specific insurance policy that has been purchased. Non-Jordanians and Jordanians with no health insurance must pay for their medications or seek medications from the UNRWA, UNHCR, or charitable organizations. ${ }^{5}$

In Jordan, the National Program of Vaccination provides the following vaccines free of charge to all children: bacille Calmette-Guérin vaccine, oral polio vaccine, diphtheriapertussis-tetanus vaccine, measles-mumps-rubella vaccine, and hepatitis B vaccine. Overall, Jordanian mothers have positive attitudes about vaccination, a situation that is associated with a high vaccination rate $(>90 \%) .{ }^{19}$

\section{HEALTH INFORMATION AND RESEARCH}

Life expectancy at birth has increased considerably for Jordanians over the past several decades, from 52.7 years in 1960 through 69.9 years in 1990 to 74.1 years in $2015 .{ }^{20,21}$ Jordan has a relatively high fertility rate $(3.5$ children per woman, as reported in 2015), but this is lower than fertility rates reported earlier (7.7 in 1960 and 5.5 in 1990). ${ }^{20,21}$ In 2015, the infant mortality rate was 15 per 1000 live births, and the maternal mortality rate was 58 per 100000 live births, both of which are lower than the previously reported rates of 34 per 1000 live births and 110 per 100000 live births, respectively, in $1960 .{ }^{20,21}$

The most common diseases encountered in Jordan are chronic illnesses. Communicable infectious diseases, such as AIDs, tuberculosis, and malaria, which are common in many developing countries, have a low prevalence in Jordan., ${ }^{5,20,21}$ According to the most recent report on noncommunicable diseases from the Jordanian Department of Statistics, about one-third of the Jordanian population over the age of 25 years 
have at least one chronic illness, the most common of which are hypertension, diabetes mellitus, and respiratory diseases. ${ }^{22}$ The most common causes of death among the Jordanian population are also chronic noncommunicable diseases, with cardiovascular diseases and cancer being the most common. ${ }^{5}$

Smoking is a major risk factor for reported chronic illnesses in the Jordanian population. Jordan has the highest prevalence of smoking, relative to countries in the Eastern Mediterranean Region and globally, with tobacco use reported for $38.4 \%$ of the total population and $65.5 \%$ of males over 15 years of age. ${ }^{5,20}$ Tobacco smoking is a health threat not only among adults, but also among children, through both first- and second-hand smoke. According to a recently published study, over one-third of students between 11 and 17 years of age reported using at least one form of tobacco (either cigarettes or water pipe). ${ }^{23}$ Although Jordan has age-limit regulations for the sale of tobacco products, the rules are not fully implemented. The use of tobacco among adolescents is a major threat to health care in Jordan, because it will increase the burden of chronic diseases and tobacco-related mortality in the future.

Medical research in the Arab countries, including Jordan, is low. ${ }^{24}$ This limits the ability of clinicians, health care institutions, and the government to understand the prevalence, risk factors, outcomes, and distribution of various diseases and conditions, which is necessary to optimize health care delivery and resource utilization. Several programs have been conducted in the Middle East to increase research productivity among health care professionals, but the impact of such programs remains limited. ${ }^{25,26}$

\section{HEALTH WORKFORCE}

The health workforce in Jordan consists mainly of physicians, pharmacists, dentists, and nurses. Other health care providers include laboratory scientists, physiotherapists, nutritionists, midwives, and medical radiation technicians. Nurses represent the majority of health workers in Jordan (44\%), followed by physicians (25\%), pharmacists (16\%), and dentists (15\%). Women constitute about $44 \%$ of all workers in the health sector in Jordan, but among pharmacists the percentage of women is higher, with more than two-thirds of pharmacists being female. 5,27

According to 2013 figures, for every 10000 Jordanians, there are 44.8 nurses and midwives, 28.6 physicians, 17.8 pharmacists, and 10.4 dentists. ${ }^{5,27}$ These per-population rates are considered among the highest in the Middle East. However, there are major geographic disparities in the distribution of health workers among the major cities and the rural governorates in the Kingdom. ${ }^{5,27}$ In addition, the country recently received about 1.4 million Syrian refugees, which has caused an unplanned increase in the population and is putting pressure on the health sector and the number of health care providers available per 10000 inhabitants. ${ }^{5,8,27}$
To practise as a pharmacist in Jordan, a person must to be registered with the Jordan Pharmacists Association (JPA) and licensed by the Ministry of Health. Registration with the JPA requires completion of a pharmacy degree (Bachelor of Science [BSc] in pharmacy or Doctor of Pharmacy [PharmD]) from an accredited school of pharmacy and completion of 1440 hours of professional training. Pharmacists with pharmacy degrees from non-Jordanian universities are required to pass a pharmacy licence examination. To maintain registration with the JPA, annual licence renewal is required. Currently, there are no continuing professional development or education requirements (e.g., credit hours of continuing pharmacy education) for licence renewal, and pharmacists are only required to pay an annual fee to renew their pharmacist licence. ${ }^{28}$

There are 15 universities in Jordan offering a 5-year BSc in pharmacy. In addition, 2 public pharmacy schools, the University of Jordan and Jordan University of Science and Technology, offer a 6-year PharmD degree. Several pharmacy schools also offer postgraduate pharmacy degrees, including Master of Science (MSc) in pharmaceutical sciences and MSc in clinical pharmacy, as well as Doctor of Philosophy (PhD) in pharmaceutical sciences and drug design. Of note, a number of community colleges offer 2-year diploma programs for pharmacy assistants. Some graduates of the diploma programs are eligible to continue their study toward a BSc in pharmacy. Currently, there are over 7000 undergraduate pharmacy students in all Jordanian universities. This is considered an alarming number of potential graduates and suggests that the supply of new pharmacists will very likely exceed the domestic demand. ${ }^{29}$

Unfortunately, pharmacy graduates with the entry-level degrees of PharmD or BSc may not be adequately prepared to practise in a clinical or hospital setting, as they lack the basic skills and knowledge to perform essential tasks such as sterile compounding, effective patient counselling, and critical appraisal of the medical literature to inform clinical decisions. ${ }^{29}$ This situation could be attributed to gaps in the university curricula and a lack of mentorship in undergraduate and postgraduate courses, since most faculty members at the schools of pharmacy do not practise in a clinical setting; hence, there is a chasm between real-world needs and challenges and the education and training offered to the students. Recently, some pharmacy schools have established virtual and simulation programs to train students in the necessary pharmacy-related skills, such as effective patient counselling and education. ${ }^{30}$

There are no structured pharmacy residency programs offered in Jordan, and those interested in doing residencies abroad face difficulty in fulfilling all of the necessary requirements for residency applications. The most common obstacle is completion of the intern hours needed to obtain a pharmacy licence. Most hospitals and community pharmacies in Canada and the United States would not sponsor foreign pharmacists 
for immigration visas to fulfill their intern hours. Therefore, most of those who seek advanced skills and knowledge in clinical pharmacy either enroll in a master's program in clinical pharmacy or rely on on-the-job training. But neither option provides the full training necessary to deliver optimal clinical services. The Royal Medical Services, one of Jordan's major public health care institutions, has a 4-year residency program in clinical pharmacy, restricted to the institution's pharmacists. However, the structure and goals of the program differ from those of pharmacy residency programs offered in Canada and the United States. The program is not accredited by an independent professional organization such as the Canadian Pharmacy Residency Board or the American Society of HealthSystem Pharmacists. In addition, although it is a 4-year program, it is closer in nature to a postgraduate year 1 residency program, which is not focused on a single specialty but rather offers rotations in all clinical specialties together with training in drug supply and distribution.

In Jordan, pharmacy practice generally involves inventory management and the preparation and dispensing of medicines. Pharmacy practice is governed by the JPA's Drug and Pharmacy Law 2001 and the Ministry of Health's Public Health Act 2008 and Narcotic Drugs and Psychotropic Substances Law 1988. ${ }^{28}$ The Ministry of Health is responsible for the registration of pharmacy premises, whereas the JFDA regulates the registration of medicines and medical devices.

Pharmacists do not have any prescribing privileges. However, the drug dispensing laws and regulations are not strictly enforced outside the hospital setting, and many medications (except for narcotics and controlled substances) are dispensed without prescriptions in community pharmacies. This practice is generally similar to what is seen in many countries within the region and puts a greater responsibility on the community pharmacist to ensure the safe and effective use of medications and to determine when medical advice is necessary. ${ }^{31}$ However, it appears that the extent to which these objectives are achieved is suboptimal. According to a recently published study, about $75 \%$ of community pharmacies surveyed reported dispensing antibiotics without a prescription. ${ }^{32}$ These findings are alarming, given that fluoroquinolones were the most common type of antibiotics dispensed to women of childbearing age without proper assessment of the patient's pregnancy status. In addition, inquiry about concomitant use of other drugs or drug allergies was not common. ${ }^{32}$

\section{HEALTH SERVICE DELIVERY}

Employment opportunities for pharmacists in Jordan are similar to those in other countries in the Middle East and worldwide. Most pharmacists work in community pharmacies, followed by pharmaceutical companies and hospitals. ${ }^{31}$

The private sector is the main employer of health workers in Jordan. About $91 \%$ of pharmacists work in private community pharmacies, private hospitals, pharmaceutical companies, and cosmetics and medical supplies companies. Public sector pharmacists work in the Ministry of Health, university hospitals, Royal Medical Services, and not-for-profit organizations such as the UNRWA. ${ }^{5}$

\section{Community Pharmacy Practice}

Community pharmacies, either pharmacist-owned or within pharmacy chains, are the most common pharmaceutical facilities in Jordan, and there are about 2500 pharmacies across the country. ${ }^{28}$ Community pharmacies provide a wide range of prescription and nonprescription medicines, as well as cosmetics, skin care products, and medical equipment. Pharmacies are highly accessible, and many patients therefore seek medical advice from pharmacists before visiting a physician. Unfortunately, patient-centred pharmaceutical care is rarely provided, and the duties of most community pharmacists remain focused on medication dispensing and inventory control. Patient counselling and education are seldom performed effectively, and very few pharmacies keep any patient records.

There are ongoing efforts to understand the barriers to providing pharmaceutical care delivery and improving community pharmacy practice in the Kingdom. The most commonly reported barriers include lack of proper education and training, low acceptance of pharmacy interventions by physicians, and lack of time to provide effective pharmaceutical care. ${ }^{33}$ The JPA launched the Good Pharmacy Practice (GPP) initiative with the mission of enhancing the role of the community pharmacist in delivering patient-focused health care. ${ }^{28}$ In this regard, the GPP initiative issued educational publications in Arabic to help pharmacists educate their patients on the proper use of medicines. The country's major pharmacy chains are embracing pharmaceutical care and the GPP recommendations by offering continuing training programs to their employees, allocating special counselling area within their pharmacies, keeping electronic medical records, and using decision support software to help pharmacists identify drug-related problems (e.g., drug-drug interactions).

\section{Hospital Pharmacy}

Hospital pharmacies can be divided into inpatient and outpatient pharmacies. The general responsibilities of hospital pharmacists include drug procurement and inventory management, order processing, medication distribution, drug information, and participation in patient safety and quality improvement initiatives. The complexity of pharmaceutical services provided and the level of integration with other departments within the hospital vary widely, depending on the vision of the particular institution, leadership within the department of pharmacy, and the requirements of accrediting organizations. Most of the leading hospitals in Jordan are accredited by the 
Joint Commission International (JCI) and/or the Jordanian Health Care Accreditation Council.

The King Hussein Cancer Center, a comprehensive cancer centre, was the first hospital in Jordan to receive JCI accreditation (in 2006) and is the only cancer centre outside the United States to be awarded JCI Clinical Care Program Certification (for its Oncology Program). Specialized clinical pharmacy services at the King Hussein Cancer Center started officially in 2005, with clinical pharmacists attending clinical rounds and offering patient counselling and documenting interventions. By 2008, this had developed into the first specialized clinical pharmacy department in the Kingdom, covering most of hospital's inpatient services and then expanding to cover ambulatory chemotherapy clinics for adults and pediatric patients. ${ }^{34,35}$

Clinical pharmacy services at the Royal Medical Services have also been progressive, particularly with the introduction of the pharmacy residency program (described above) and investment in staff development through professional training and education toward advanced clinical pharmacy degrees. Clinical pharmacy services are also provided at the university hospitals, some Ministry of Health hospitals, and some leading private hospitals in the country.

Despite this progress in hospital pharmacy practice, pharmacists in hospitals represent a small proportion of the overall pharmacy workforce (about 500 pharmacists) ${ }^{28}$ In addition, the majority of pharmacists starting their work in a hospital pharmacy may not have the necessary skills and training to work in such a setting. ${ }^{29}$

\section{Pharmaceutical Industry}

The Jordanian pharmaceutical industry has grown remarkably over the past 4 decades. Currently, there are 16 drug manufacturing companies in the Kingdom, after accounting for mergers and restructuring during the past 2 years. ${ }^{14}$ Jordan joined the World Trade Organization in 2000, which reduced export barriers and lowered industry tariffs.

About $80 \%$ of pharmaceutical production is exported to over 60 global markets, making the pharmaceutical sector a key contributor to Jordan's economy. ${ }^{14}$ Pharmacists in local pharmaceutical companies work in research and development, quality control, regulatory affairs, or sales and marketing. In addition, there are several offices for multinational companies in Jordan, where pharmacists work in sales and marketing or medical departments. Notably, sales and marketing jobs attract a high percentage of Jordan's pharmacy graduates because of the relatively high salaries and other benefits (e.g., car allowance), which contrast with the limited opportunities and compensation available in hospital and community pharmacies.

\section{Other Sectors}

Pharmacists in Jordan also work in regulatory bodies such as the JFDA, universities (as academics and researchers), research institutions, and drug information centres, including the Jordan Drug Information and Toxicology Center at the Royal Medical Services, the Drug Information Center at the King Abdullah University Hospital, and the Jordan National Drug and Poison Information Centre at Jordan University Hospital.

The role of the pharmacist in both public and private primary care clinics is limited. Some of the multiclinic centres have their own pharmacies, which generally keep limited quantities of essential medicines and are run by pharmacists or pharmacy technicians. The role of the pharmacist in such pharmacies is mostly restricted to dispensing medications and inventory management.

\section{FUTURE DIRECTIONS}

Health care and pharmacy practice in Jordan have advanced considerably over the years. However, there remain several aspects that should be addressed to further enhance the quality of health care.

In particular, there is a need to revise the current pharmacy curriculum to put more emphasis on direct patient care and to meet the current needs of the Jordanian market. Developing residency programs is also essential to provide the necessary training in clinical practice, particularly in specialized pharmacy services. To ensure the continuing education of practising pharmacists, the completion of professional development credit hours should be included as one of the requirements for annual renewal of a pharmacy licence.

In community pharmacy, initiatives such as the GPP should be incorporated in all pharmacies to improve overall practice. In addition, because pharmacists in the community setting are often the first health care providers approached for medical advice, giving them the necessary knowledge and skills on how to manage commonly encountered situations and how to counsel patients is essential. Community pharmacists can also assume more responsibilities in improving public health. Developing smoking cessation programs in the community would be of great importance to address one of the major risk factors for chronic illnesses among Jordanians.

The role of hospital pharmacists should be expanded toward more clinical duties and integrated services with other hospital departments. Automation and technician empowerment can help free up pharmacists' time for more patientfocused duties. Hospital pharmacists can also play a major role in clinical and pharmacy-related research that would help demonstrate the value of the pharmacists in health care and in optimizing patient outcomes.

Pharmacoeconomics is of great importance in a country with limited resources. There is a need to develop capacity in this field and to establish clear guidelines for various types of pharmacoeconomic assessments in Jordan.

In conclusion, Jordan has a well-established health care system but there remains a need to address and expand several 
aspects such as home health care, medical coverage for refugees, medical research, and the role of the pharmacist in delivering pharmaceutical care. Although there is increased awareness about the potential value of pharmacists in delivering pharmaceutical care, pharmacy practice in many settings remains focused on inventory management and the preparation and dispensing of medicines.

\section{References}

1. About Jordan: facts about Jordan. Amman (Jordan): Government of Jordan; [cited 2016 Sep 5]. Available from: www.jordan.gov.jo

2. Population and housing census 2015. Amman (Jordan): Department of Statistics; 2016 [cited 2016 Sep 5]. Available from: http://census.dos.gov.jo/ wp-content/uploads/sites/2/2016/02/Census_results_2016.pdf

3. Research/survey/statistics. Medical tourism and healthcare status from around the world. Medical Tourism Association [cited 2016 Sep 5]. Available from: www.medicaltourismassociation.com/en/research-and-surveys.html

4. Everybody's business: strengthening health systems to improve health outcomes. WHO's framework for action. Geneva (Switzerland): World Health Organization; 2007 [cited 2016 Sep 5]. Available from: www.who.int/ healthsystems/strategy/everybodys_business.pdf

5. The national strategy for health sector in Jordan 2015-2019. Amman (Jordan): Hashemite Kingdom of Jordan, High Health Council; [cited 2016 Oct 20]. Available from: www.hhc.gov.jo

6. UNRWA: Health in Jordan. United Nations Relief and Work Agency for Palestine Refugees in the Near East; [cited 2016 Oct 20]. Available from: www.unrwa.org/activity/health-jordan

7. UNRWA: What we do. United Nations Relief and Work Agency for Palestine Refugees in the Near East; [cited 2016 Oct 20]. Available from: www.unrwa.org/what-we-do/services

8. Murshidi MM, Hijawi MQB, Jeriesat S, Eltom A. Syrian refugees and Jordan's health sector. Lancet. 2013;382(9888):206-7.

9. Doocy S, Lyles E, Akhu-Zaheya L, Oweis A, Al Ward N, Burton A. Health service utilization among Syrian refugees with chronic health conditions in Jordan. PLoS One. 2016;11(4):e0150088.

10. About Hakeem. Amman (Jordan): Electronic Health Solutions International; [cited 2016 Oct 20]. Available from: http://ehs-int.com/about-hakeem

11. Overview of Jordan's National VistA Implementation Initiative. WorldVistA; [cited 2017 Feb 9]. Available from: http://199.180.113.45/Conferences/ conference_presentations/19th-vista-community-meeting-1/WorldVistA $\%$ 20VCM\%20NLM\%20Jordan\%20180609.pdf/view

12. Electronic Library of Medicine: about us. Electronic Library of Medicine; [cited 2017 Sep 9]. Available from: https://www.elm.jo/CustomPage/184

13. Jordan population and housing census 2015. Amman (Jordan): Department of Statistics; [cited 2016 Oct 20]. Available from: http://census.dos.gov.jo [website in Arabic].

14. Pharmaceutical industry. Amman (Jordan): Jordanian Association of Pharmaceutical Manufacturers; [cited 2016 Oct 20]. Available from: www. japm.com/Public/English.aspx?Lang=2\&Page_Id=194\&Menu_ID=6\&Men u_Parent_ID=-1\&type=R

15. Jordan Food and Drug Administration [homepage]. Amman (Jordan): The Administration; [cited 2016 Oct 25]. Available from: www.jfda.jo

16. Hammad EA. The use of economic evidence to inform drug pricing decisions in Jordan. Value Health. 2016;19(2):233-8.

17. Al-Abbadi I, Qawwas A, Jaafreh M, Abosamen T, Saket M. One-year assessment of joint procurement of pharmaceuticals in the public health sector in Jordan. Clin Ther. 2009;31(6):1335-44.

18. Lafi R, Robinson S, Williams I. Economic evaluation and the Jordan Rational Drug List: an exploratory study of national-level priority setting. Value Health . 2012;15(5):771-6.

19. Masadeh MM, Alzoubi KH, Al-Azzam SI, Al-Agedi HS, Abu Rashid BE, Mukattash TL. Public awareness regarding children vaccination in Jordan. Hum Vaccin Immunother. 2014;10(6):1762-6.

20. Eastern Mediterranean Region: Framework for health information systems and core indicators for monitoring health situation and health system performance.
Geneva (Switzerland): World Health Organization; 2016 [cited 2016 Oct 25]. Available from: http://applications.emro.who.int/dsaf/EMROPUB_ 2016_EN_19169.pdf?ua=1\&ua=1

21. Data for countries and economies: Jordan. World Bank Group; 2016 [cited 2016 Oct 25]. Available from: data.worldbank.org/country/Jordan

22. Chronic illnesses in Jordan, 2010 [in Arab]. Amman (Jordan): Department of Statistics; 2011 [cited 2016 Oct 25]. Available from: www.dos.gov.jo/ dos_ home_a/main/Analasis_Reports/dis_perment_2010/dis_perment_2010.pdf

23. Alzyoud S, Kheirallah KA, Weglicki LS, Ward KD, Al-Khawaldeh A, Shotar A. Tobacco smoking status and perception of health among a sample of Jordanian students. Int J Environ Res Public Health. 2014;11(7):7022-35.

24. Benamer HTS, Bakoush O. Arab nations lagging behind other Middle Eastern countries in biomedical research: a comparative study. BMC Med Res Methodol. 2009;9:26.

25. Chouchane L, Mamtani R, Al-Thani MH, Al-Thani AA, Ameduri M, Sheikh JI. Medical education and research environment in Qatar: a new epoch for translational research in the Middle East. J Tansl Med. 2011;9:16.

26. Nazer LH, Tuffaha $\mathrm{H}$, Jaddoua $\mathrm{S}$. A program to increase research productivity among hospital pharmacists. J Pharm Pract. 2016 Apr 24. pii:0897190016645432 [Epub ahead of print].

27. National human resources for health observatory annual report, 2013. Amman (Jordan): Hashemite Kingdom of Jordan, High Health Council, General Secretariat; 2014 [cited 2016 Oct 25]. Available from: www.hhc.gov.jo/ uploadedimages/HRHReport2013.pdf

28. Pharmacy profession in Jordan. Amman (Jordan): Jordan Pharmacists Association; [cited 2016 Oct 25]. Available from: http://jpa.org.jo/page/ pharmacy-profession-jordan

29. Bader LR, McGrath S, Rouse MJ, Anderson C. A conceptual framework toward identifying and analyzing challenges to the advancement of pharmacy. Res Social Adm Pharm. 2017;13(2):321-31.

30. Basheti IA. The effect of using simulation for training pharmacy students on correct device technique. Am J Pharm Educ. 2014;78(10):177.

31. Kheir N, Zaidan M, Younes H, El Hajj M, Wilbur K, Jewesson PJ. Pharmacy education and practice in 13 Middle Eastern countries. Am J Pharm Educ. 2008;72(6): 133 .

32. Almaaytah A, Mukattash TL, Hajaj J. Dispensing of non-prescribed antibiotics in Jordan. Patient Prefer Adherence. 2015;9:1389-95.

33. Aburuz S, Al-Ghazawi M, Snyder A. Pharmaceutical care in a communitybased practice setting in Jordan: where are we now with our attitudes and perceived barriers? Int J Pharm Pract. 2012;20(2):71-9.

34. Tuffaha HW, Koopmans SM. Development and implementation of a method for characterizing clinical pharmacy interventions and medication use in a cancer center. J Oncol Pharm Pract. 2012;18(2):180-5.

35. Tuffaha HW, Abdelhadi O, Omar SA. Clinical pharmacy services in the outpatient pediatric oncology clinics at a comprehensive cancer center. Int $J$ Clin Pharm. 2012;34(1):27-31.

Lama H Nazer, PharmD, BCPS, is with the Department of Pharmacy, King Hussein Cancer Center, Amman, Jordan.

Haitham Tuffaha, MSc, MBA, PhD, is with the School of Medicine, Griffith University, Gold Coast, Queensland, Australia.

Competing interests: None declared.

\section{Address correspondence to:}

Dr Lama H Nazer

Department of Pharmacy

King Hussein Cancer Center

Queen Rania Al-Abdallah Street

PO Box 1269

Amman 11941 Jordan

e-mail: Inazer@khcc.jo 